\title{
Suggestions for Developing a Professional Team of Civil Helicopter Rescuers
}

\author{
Weiwei Zhu \\ Waterborne Transport Research \\ Institute of MOT, \\ Beijing, China
}

\author{
Hao Wang \\ No.1 North Flying Service of MOT, \\ Yantai, China
}

\author{
Ting Sun \\ Waterborne Transport Research \\ Institute of MOT, \\ Beijing, China
}

\begin{abstract}
Based on the overall socioeconomic conditions and in response to the strategic requirements of law-based governance and maritime power development, this paper focuses on the ways to implement MOT (Ministry of Transportation) Guidelines on Improving Expertise in Salvage. Based on the guidelines, the article offers suggestions on how to enhance capacity of air emergency rescuing and how to develop a professional team of helicopter rescuers.
\end{abstract}

Keywords-emergency rescue system; civil helicopter rescuer; flying service

\section{INTRODUCTION}

Air emergency rescue system is a vital part of the national emergency rescue system, featuring strong expertise requirements, complex technical and logistic support systems and demanding management skills. Among methods on emergency rescue, helicopter rescue has the advantage of high mobility, good performance, broad coverage and ability of performing tasks in highly complicated sea conditions, and is thus attached greater importance. Based on the overall socioeconomic conditions and in response to the strategic requirements of law-based governance and maritime power development, this article offers suggestions, in accordance with the principle of "improving the system in a scientific way, leading an orderly development by setting up standards, achieving sustainable development, strengthening regulation and ensuring secure development" and consistent with MOT (Ministry of Transportation) Guidelines on Improving Expertise in Salvage, on ways to develop a professional team of civil helicopter rescuers.

\section{STATUS-QUO OF CIVIL HELICOPTER RESCUE AND REQUIREMENTS FOR ITS FURTHER DEVELOPMENT}

Since 2001, Ministry of Transportation has organized four air emergency rescue teams, namely, No.1 East Flying Service, No.1 North Flying Service, No.1 South Flying Service and No.2 East Flying Service. The coverage of our flight rescue system has been extended to Bohai Bay, Yangtze River Estuary, Taiwan Strait, Qiongzhou Strait, Xisha Islands and other sea areas of focus. We have practically built a trinity salvage system, covering air emergency rescue, water surface emergency rescue and underwater salvage. According to National Plans for Building Systems of Water Safety
Monitoring and Salvage issued by the State Department, by 2020, airports specialized for the use of salvage will be built in three comprehensive bases in Yantai, Shanghai (where such airports already exist) and Sanya. Flight resue bases (used for landing) will be built in 17 regions, namely, Dalian, Qinhuang Island, Tianjin, Yantai, Qingdao, Lianyugang, Shanghai, Zhoushan, Wenzhou, Fuzhou, Xiamen, Shantou, Zhuhai, Zhanjiang, Beihai, Sanya and Three Gorges Reservoir Area. Such a salvage system ensures full coverage of China's coastal area. (For details, please refer to Deployment Diagram for Existing Flight Rescue Bases and the Bases to be Completed by 2020)

Currently, we have twelve flight rescue bases and sixteen civil helicopters at our disposal for performing tasks on call. By the end of 2014, we had performed 2688 tasks of salvage. The number of flights deployed totaled 3970 and the number of people we rescued totaled 3407.

We have undeniably achieved progress in the civil helicopter rescue industry, but compared with developed countries, our system for building a professional rescue team still has room for improvement, especially in the system for recruiting and training personnel. The severe shortage of flight rescue personnel has become an issue constraining the performance our helicopter rescue tasks. Since different flying rescue teams differ in their models for training, day-to-day functioning and management, an integrated training system is lacking, which undermines efficiency and the long-term development of rescue team. Our system for managing the rescue team is still in its primary stage of development, and we have not attached enough importance to the role that helicopter rescuers play. In addition, a sound system for management of emergency rescuers, and that for drilling and evaluation is absent. Meanwhile, the salvage industry falls into the category of public service and has huge implications for life-saving issues. Such a nature requires that the state need to rationalize its allocation and distribution of compensation and training fees suited to the characteristics of this industry so as to meet the needs for retraining.

According to the Guidelines for the Development of Middle-to-long Term Expertise in the Salvage System, by 2020, we should have at least 40 rescue aircrafts at our disposal. According to industrial standard, each aircraft should 
be equipped with two pilots and two to three flight rescuers (among which at least one is winchman), and based on this calculus, each of our bases should have 80-120 qualified flight rescuers (among which forty or so are winchmen) to meet the demand. The submariners we recruited before have now all been trained into professional trainers of rescuers, and the number of rescuers has been increased from 3 to 64, among which are 6 trainers of rescuers, 18 winchmen, 40 rescuers. Such a rescue team is qualified to perform current tasks, but those tasks are performed at the expense of the rest and recuperation of personnel, which imposes a negative effect on the timeliness and security of salvage in a direct or indirect way.

TABLE I. StAFF COMPOSITION OF RESCUE TEAMS BY THE END OF 2015

\begin{tabular}{|c|c|c|c|c|c|}
\hline & Total & $\begin{array}{c}\text { No.1 } \\
\text { North }^{\mathrm{a}}\end{array}$ & $\begin{array}{l}\text { No.1 } \\
\text { East }^{\text {b }}\end{array}$ & $\begin{array}{l}\text { No.2 } \\
\text { East }^{\mathrm{c}} \\
\end{array}$ & $\begin{array}{c}\text { No.1 } \\
\text { South }^{\mathrm{d}}\end{array}$ \\
\hline Total Staff & 521 & 156 & 169 & 96 & 100 \\
\hline Cadres & 21 & 5 & 5 & 6 & 5 \\
\hline Pilots & 60 & 20 & 18 & 9 & 13 \\
\hline Crew & 131 & 39 & 32 & 25 & 35 \\
\hline $\begin{array}{c}\text { Rescuers, } \\
\text { Winchmen }\end{array}$ & 64 & 17 & 14 & 15 & 18 \\
\hline Flight Operators & 61 & 23 & 18 & 10 & 10 \\
\hline Logistic Personnel & 164 & 56 & 61 & 24 & 23 \\
\hline \multicolumn{6}{|c|}{$\begin{array}{l}\text { a. No.1 North is the abbreviation of No.1 North Flying Service } \\
\text { b. No.1 East is the abbreviation of No.1 East Flying Service } \\
\text { c. No.2 East is the abbreviation of No.2 East Flying Service } \\
\text { d. No.1 South is the abbreviation of No.1 South Flying Service }\end{array}$} \\
\hline
\end{tabular}

Therefore, based on the requirements for civil helicopter emergency rescue work and for optimizing the structure of personnel, we should improve our system for the recruitment, introduction, training, development, evaluation and protection of helicopter rescuers. We will actively promote innovation of our research on the policies and regulations, theories and techniques, systems and mechanisms. We shall build a management system suited to the development of a qualified helicopter rescue team. We should build a comprehensive and standardized system, and press ahead with the revision of crucial standards. We should enhance the skills of helicopter rescuers and provide them with a long-term training system throughout their career development and imbue a sense of accountability in them. All these measures constitute a vital method for developing a helicopter rescue team that is ready to be deployed, resistant to highly complicated sea conditions and that responds quickly, operates safely and efficiently. In this way, our rescue team can meet the needs of emergency rescue over sea and is qualified to perform demanding national salvage tasks.

\section{Suggestions for DeVEloping a Professional Flying RESCUE TEAM}

\section{A. Strengthening the Management System}

We should improve the system for managing rescuers and relevant mechanisms. We should develop regulations for specific departments and follow the working process for setting, revising and relinquishing standards. We should establish a supervision system that clearly defines duties and responsibilities of each personnel. We should standardize the staffing process, improve administration by different levels featuring self-discipline. We should gradually establish a sound mechanism for recruiting and incentivizing personnel.

We should improve the regulation of the institutions related to the training and evaluation of flight rescuers, the development of equipment and the issuance of certificates. We should standardize our management of professional entrance and set up unified regulations for qualification accreditation. We should establish a dynamic mechanism for managing training institutions and make efficient inspections on existing accredit ted institutions. We should strictly regulate the market for training helicopter rescuers and carry out clean-up and rectification on a regular basis.

We should improve the regulation of the recruitment process. We should strictly abide by the recruitment policies and implement the recruiting policies and relevant provisions in an all-round and transparent way. The employing institutions should, in accordance with the principle of testing the skills that are truly required, determine the content of the examination suited to the requirements of the job. We should improve recruitment, examination and evaluation, and we will conduct research on these matters. We should clearly define distribution of duties to ensure the establishment of a system of accountability and the improved result of recruitment.

We should regularize and institutionalize the training and evaluation of flight rescuers. We should establish standards for training and evaluation and improve their implementation. We should establish a sound mechanism for training and evaluation so as to achieve better training results. We should intensify our training and evaluation of personnel, retain the existing personnel and improve their professional competence.

We should establish a system of training that features unified and standardized curriculum, pedagogical methodology, training mechanism and evaluation method. In response to the salvage tasks that helicopter rescuers perform, we should integrate practical concerns into our courses, improve the theory and knowledge system and keep a close watch on the operating process. We should design an allround training program with well-developed training methods and revise them when necessary. We should improve our evaluation method so that it be scientific and appropriate.

\section{B. Pressing Ahead with the Development of System of Regulations}

We should strengthen the development our regulations and establish a system standards. We should clearly define the legal status of national professional salvage teams and bring the vocation of helicopter rescuers into the national job category, and establish a sound vocational accreditation system. We should conduct research on and establish a system of salvage standards. We should actively promote research on the establishment of standards on personnel, techniques, equipment and management. We should establish a standardized internal management system. We should actively participate in the legislation and regulations of international salvage. 


\section{Promote the Development of System of Safeguards and Guarantees}

We should improve the overall expertise of helicopter rescuers. We should develop a team of backbone expertise capable of setting the direction for techniques and performing pedagogical tasks in order to ensure the "spread, guidance and promotion" of techniques. We should conduct research on capacity-building for helicopter rescuers and improve their scientific and educational level. We should improve the overall moral standards and carry training activities in various forms so as ensure constant improvement of political qualities and mastery of relevant theories.

We should improve the staffing of institutions and establish a sound system of recruiting, training, incentivizing and compensating helicopter rescuers. We should tackle the shortage of official budgeted posts through coordination. Based on the institutional and personnel management system, we should establish a sound system of recruitment, promotion and evaluation. We should allow mobility of our team of professionals so as to provide incentives for helicopter rescuers to improve their performance. We should take the characteristics and risks of flight rescue into the consideration for a reasonable compensation system that values actual performance and contribution.

We should improve cultural development and establish a highly-qualified professional team. We advocate a right world view, vision of life and values. We should improve the education of our national conditions and professional etiquette. We should improve the sense of responsibility, accountability and commitment of our team, and imbue a core value of salvage into our salvage team. We should improve the publicity of our relevant policies. And we should ensure that our salvage system has a good public image and increase its international influence so as form a solid foundation for recruiting helicopter rescuers.

We should improve the humanistic care of our helicopter rescuers and establish a sound system of safeguards and guarantees. We should carry out the basic guaranteeing policies and establish a service system that is guided by the government, implemented by employing institutions and supported by society. We should establish mechanisms of tracking the mental state of employees and conduct mental consultation on a regular basis. We should establish a system of annual physical examination and improve our medical care. We should encourage employees to go on vacation or recuperation at regular intervals. We should resolve the issues of employment of personnel's relatives and schooling of their children. We should provide personalized service for our personnel.

We should improve our infrastructure. We should advance construction of professional training facilities, training grounds and training centers of helicopter rescuers. We should press ahead with the research on the development of professional training and rescue equipment. We should fully improve the efficiency of our training facilities and equipment. And we should improve the training results and our ability of safeguards and guarantees.

\section{SUGGESTIONS}

We should strengthen the leadership of our organization, clearly define the responsibilities, improve the regulation and inspection and establish a system of accountable supervision. We should attach importance to the development of a team of helicopter rescuers, detail the division of work, intensify our regulation. We should adopt a holistic view in our publicity and supervision work so as improve our quality management system. We should imbue the concept of establishing a professional team into our salvage work. We should hold directors and specific group leaders accountable for those who work against our guidelines.

We should develop a standard work group of helicopter rescuers and conduct research on setting up relevant standards. We should develop an integrated system of production, study and research, and broadly engage experts within and outside the industry. We should standardize our work, coordinate our salvage work with unified system of techniques, management and service. We should conduct research on setting up relevant standards. For the established standards, we should keep a close track of their implementation. For those unsuitable for the development of industry and technological development, we should timely research and revise them.

We should implement a strategic system for managing personnel. We should develop a strategy for managing helicopter rescue talents. We should combine the long-term development of personnel and short-term training and develop a comprehensive training system with well-developed plans, gradual stages and targeted focus. We should develop a development program for managing highly-qualified personnel. We should press ahead with research on job rearrangement mechanisms of aging employees and improve safeguards and guarantees.

We should ensure the development of financing mechanisms. We should increase financing for projects related to research on policy standards, salvage techniques, equipment procurement and training facilities in response to the requirements of salvage tasks and personnel training. We should attach great importance to the specialized training and supervision and inspection. We should improve efficiency of the utilization of funds. We should ensure the secure, regulated and efficient use of funds.

\section{CONCLUSION}

Director Wang Zhenliang of the Salvage Bureau of the Ministry of Transportation has stressed in the 2016 Conference on Salvage System that, during the $13^{\text {th }}$ Five Year Plan, the strategic implementation of “One Belt, One Road”, "Strengthening the Country by Developing Maritime Power" and "Strengthening the Country by Developing Maritime Transportation” initiatives has moved to a new stage. The strategy of "Strengthening the Country by Developing Transportation" has imposed new requirements on the 
safeguards and guarantees of our salvage system. The new characteristics of waterborne transportation have enabled us to extend safety guarantees to water areas of focus. Water safety guarantees are faced with new situations and salvage work is confronted with new challenges. Whether we can develop specific policies for developing a "civil helicopter rescue team that is ready to be deployed, resistant to highly complicated sea conditions and that responds quickly, operates safely and efficiently and capable of performing emergency rescue and other national salvage tasks over sea" determines the implementation of relevant policies. In this way, we will be able to resolve relevant issues that we might confront during the establishment of a system of guarantees for water salvage, sea lanes and the implementation of national strategies of "One Belt, One Road", "Strengthening the Country by
Developing Maritime Power" and "Strengthening the Country by Developing Maritime Transportation”.

\section{References}

[1] Published by the Ministry of Transportation China, Guidelines on Improving Expertise in Salvage, Jul.2014.

[2] LIU Jian, XIN Jing, YANG Qing, On the Lifesaving Training at Sea for the Troops, J. PLA Institute of Physical Education. Vol.24 No.3, Jul.2005, 30-32.

[3] ZHAO Shiye, The Position and Development of the Diving Rescue Team in the National Water Emergency Industry, J.CWT , Jul.2015, 18 20.

[4] Information on http://www.crs.gov.cn/

[5] Information on https://en.wikipedia.org/ 